\title{
Age and Gender's Association with Information \& Communication Technology (ICT) Usage into Educational Institutions of Pakistan
}

\author{
Adnan Adil ${ }^{1}$, Muhammad Masood ${ }^{2}$, Matloob Ahmed ${ }^{1}$ \\ ${ }^{1}$ Institute of Social \& Cultural Studies, University of the Punjab, Lahore, Pakistan \\ ${ }^{2}$ Department of Sociology, University of Gujrat, Gujrat, Pakistan \\ Email: adnanadi187@yahoo.com
}

Received August 14 $4^{\text {th }}, 2013$; revised September $18^{\text {th }}, 2013$; accepted October $2^{\text {nd }}, 2013$

Copyright (C) 2013 Adnan Adil et al. This is an open access article distributed under the Creative Commons Attribution License, which permits unrestricted use, distribution, and reproduction in any medium, provided the original work is properly cited.

\begin{abstract}
Information \& Communication Technology (ICT) usage in Pakistan is growing trend. However, while there is expanded concern of knowledge about how ICT is in usage in low income countries, there is information lacking on how ICT is used by the university teachers in low income countries. This research studied perception of university teachers about use of ICT, in Pakistani universities. The research through purposive sampling was drawn on 57 teachers, belonging to the public sector universities of Lahore, Punjab, Pakistan. This survey consisted of 29 males and 28 females. Their ages vary from 26 to 50 years. Open-ended questionnaire was used for this survey. It also showed that respondents have availability of internet at office. The association between different variables was calculated from chi-square test, and the strength of association was measured by gamma. The result showed the moderate negative association between level of age and quantity of daily time spent on computer. It also showed that no association exists between category of teacher's gender and quantity of daily time spent on computer. For enhancement of ICT integration into education, it was recommended that teachers must have access to infrastructure relating ICT and there should be provision of sufficient training to teachers.
\end{abstract}

Keywords: ICT; Education; Age; Gender

\section{Introduction}

From agrarian age to the industrial age, and now the information age, society has experienced many gigantic changes as discussed by Reigeluth (1995). These radical changes have certainly affected today's education systems at various levels (Goktas \& Yildrim, 2003, cited in Bhukuvhani et al., 2011). The want to put together Information and Communication Technologies (ICT) into education is now inevitable (Goktas \& Yildrim, 2003, cited in Bhukuvhani et al., 2011). The significance of the integration of ICT into education could be realized as in 2002. Alone the United Sates government invested approximately 3.2 billion dollars on only K-12 related technology projects (Market Data Retrieval MDR, 2003).

Incorporation of ICT into education is a critical matter. ICT has had a very significant role in enhancing the quality of education. The function of ICT is to serve up education in particular, by helping students to learn and teachers to perform their teaching profession more effectively (Goktas \& Yildrim, 2003, cited in Bhukuvhani et al., 2011). It is also crucial to understand that because of the abundance of these technologies, their effective use is a real issue (cited in Bhukuvhani et al., 2011). Reigeluth and Joseph (2002) distinguish between technology integration and technology transformation. They point out that technology integration focuses on "how to make use of tech- nology to hold up the way teaching is currently done in the schools?" whereas technology conversion emphasizes the exercise of technology to teach what was not possible when the technology was unavailable (Su, 2009). However, for Ertmer (2005), technology transformation is actually an effective technology integration. In her view, technology adds value to the curriculum not by its "quantitative changes" such as "doing more of the same in less time", but by its "qualitative changes" such as accomplishing more authentic and complex goals ( $\mathrm{Su}$, 2009). Thus, effective technology integration is required into the learning in its place of simply using technology to carry on the aged mode of instruction and learning.

Education as a social enterprise is a composite of many stakeholders such as teachers, students, parents, administrators, business partners and policy makers. To effectively integrate technology, these people will either affect or be affected by the change (Su, 2009).

Therefore, a systematic change is needed to effectively integrate technology into the classroom instead of a fundamental change. Reigeluth (1994) emphasis that systemic change is a paradigm shift that "entails the change of the whole thing" because "a fundamental change in single phase of a arrangement requires elementary changes in supplementary aspects in order for it to be successful". 


\section{Pakistani Society}

History of different civilizations depicts that politics and economy had ever remained the fundamental determinant of the civilizations but the institution of education had also remained one of the primary functions of society. Geography, linguistics, philosophy, culture, religion and morality are the formative factors of education. All these define the syllabus of education. But certain factors had always remained there, which made education more influential. Technology is one of the greatest factor in this regard. Technology is knowledge through which people establish their surroundings (Macionis, 2006). Technology was used during all the periods of human civilization. With the evolution of technology, educational system also evolved.

When Pakistan came into existence, the world had reached the post industrial technological stage. Now Pakistan had many challenges in front of it. It had to strengthen its educational foundations as well as technological grounds (Ashraf, 2010). At the earlier stage Pakistan could not do much for the integration of technology into education. But with the passage of time, Pakistan took strong decisions and made policies regarding integration of technology into education.

If we study the historical evolution of technological integration into education, we shall come to know that during first 40 years after Pakistan creation, no strong step in this regard was taken in any educational policy. For the very first time this concept was introduced in the educational policy of 1998. In this educational policy it was promised that education would be modernized in Pakistan through introducing information and communication technology. In all level of classes, computer would be taught. Students would be motivated to work with computer. It was also planned to provide internet facility in libraries in order to acquire knowledge at international level to solve the problem of lack of books and other reading materials. This policy was also determined to provide guidance and training to the teachers about information and communication technology. It was also promised that computer science would be introduced in secondary and higher educational institutions periodically. There were intentions to establish national council for technical education (Ashraf, 2010).

In Musharraf regime, a task force was established to improve the level of higher education. With the recommendations of this task force "Higher Education Commission" was established. Which also focused upon the dire need of ICT integration into education? During this regime Dr. Atta-ur-Rehman was made the minister for education. He developed ICT into education in such a tremendous manner, that it resulted into a great revolution in the field of education (Ashraf, 2010). Educational institutions were provided with the modern technology. For the first time it seemed that ICT had not only made easy interaction between different educational institutions, but also had decreased the ratio of effort. Through internet different educational institutions were affiliated with international libraries. This methodology paved the way of researches to get latest information.

Higher Education Commission (HEC) took strong decision in promotion of educational affiliation with modern technological trends. It established the digital library, because of which almost, every public and private university was given with the access to online books, articles, journals, newspapers and other reading materials of foreign publishers.
The concept of video conferencing in Pakistani educational institutions was also introduced by HEC. This concept was introduced with the intention to decrease the interaction gap between teachers and students.

This concept also resulted as a revolution in education sector. This promoted the concept of distance learning. In 2006, eminent scholars from Pakistan delivered video lecture on different topics to international and national students through video conferencing. Then in the next phase, the lectures of eminent schoolars from all over the world were recorded (Ashraf, 2010). In 2008 there were 54 sites which were functioning all over the country arranging the recorded lectures, seminars and conferences. National Educational Policy was also a step forward to the execution of technical advancements in the ground of tutoring.

In National Education Policy of 2008, establishment of a mechanism of creating an excellent planning to fulfill the educational criteria in global perspective was planned. Pakistan needed to perform equally as the performance of India in the field of ICT. This policy also pointed out specific problems relating to ICT integration into education. Many institutions promoted this field with clear demarcation of their responsibilities (National Education Policy, 2008). In National Educational Policy of 2009, strengthening skill development and to introduce modernity in field of education was again planned.

Then in 2012, Punjab government took a strong decision in promotion of information and communication technology in educational sector. About one Lac students were given with lap tops. With this facility Punjab government also provided facility of internet in different universities, colleges etc. This was a revolutionary step in educational development.

As it is discussed Pakistan could not pay concentration towards ICT integration into education, soon after its creation Pakistan could introduce this technology into education in late 1990s. Certain factors were there, which were responsible for this delay.

Quickly, after the creation of Pakistan, it came under the Burden of crises. Settlement of migrants, making of constitution, political instability, hurdles in the way of democracy, war of 1965, war of 1971 and other crises influenced the educational polices. These crises did not allow the policy makers to concentrate on the social institution of education because of which we could not achieve ideal goals in the field of education, in earlier years of Pakistan creation (Ashraf, 2010).

Then there were also some ideological contradiction, because of which there was delay in arrival of communication technology like computer, internet, multimedia and video conferencing etc. certain theological ideologies were there which were preaching that using of latest technology had some contradictions with religion. So there was a gap between arrival of technology and its usage in Pakistan (Siddiquei, 2008).

Another hurdle in this regard was that teachers had no knowledge about use of ICT. So they were not able to guide and teach their students about latest technology during education. Then different educational policies were made in which it was promised that ICT should be introduced in educational system but these policies could not be implemented. Then nationalization and privatization policies also caused the delay in the promotion of ICT into education. The institutions which became privatize, adopted the latest and modern technology at rapid pace, while nationalize institutes adopted this technology at slower peace which depicted the variable of class difference. Which 
means that class differed causes learning gap among students, belonging to different social classes? (Shah, 2001)

Policy makers of education in Pakistan will have to take certain steps for the establishment of technological modernity's in the social institutions of education. Training of teachers should be organized on a large scale, in which there must be provision of guidance about using modern technological equipment like computer, multimedia etc. importance of the usage of ICT into education should also be elaborated to teachers.

All the educational institutions should be provided with latest technological equipments. Especially, it is much needed in universities. Because easy access of ICT can improve the knowledge of students about using it. Because if government is not providing such kind of material, then students are not able to afford such technological equipment, on their own behalf. (Shah, 2001) then technology usage efforts of teachers should be rewarded instructional activities. And there should be reduction of load and burden on teachers for developing instructional material.

The current topic of research focused to trace the factors that are affecting ICT integration into education in Pakistan. For example how gender, age, teaching subject and time are associated with ICT integration into education. In this research, for the first time, it is tried to trace the category of gender and its association with ICT. Have male and female an equal access of information and communication technology in education sector. In April 2000, the government of our country established National Plan of Action (NPA) on education for all 2001-2015. The basic aim of this was to end gender discrimination in field of education. A commitment was made to provide compulsory education to all male and female. Even in the 18th Amendment, according to article 25 (a), free and compulsory education for both male and female uphill the age of sixteen was recommended. This was a strong step to end gender and economic discrimination at primary level.

To sum up the discourse we can say that historically, ICT in Pakistan evolved in education at sallower pace. This was because of crises in Pakistan as well as because of demerits in the interval structure of educational system itself. Then there was also demerit in the implementation of polices related to ICT in education. But after 2000, dramatic changes occurred, and teachers as well as students were acquainted with ICT. This study is an effort to probe ICT integration into education, by measuring the perception of university teachers in Pakistan.

\section{Literature Review}

Importance of the literature review lies in the fact that it provides us the background knowledge of the relevant topic. It does tells, to what extent this topic had been explored by other researchers. It provides guideline for the specification of our topic and to make unique from other researcher. By reviewing the previous studies, researcher also gets awareness about the suitable methodology, which he can use in his research. In the following situation, the summary of different studies, which are relevant to the present study, are being elaborated.

Adeyinka (2007) examined Nigeria secondary school teachers' uses of ICT and its implications, for further development of ICT use in Nigerian secondary schools. The study through census drawn on 700 teachers from twenty five tenaciously chosen classified resultant schools in Ibadan, Oyo state, Nigeria. The results showed that teachers generally have way in to ICT in their diverse schools except e-mail and Internet because their schools are not connected. In addition, the outcome illustrates that teachers supposed ICT as being easier and very useful in teaching and learning. Current research is also following the survey technique for data collection. But the study is not controlled as an Adeyinka research, such respondents were studied who have no access to email and internet. But current study is going to explore the universities, where generally email and internet are available so it is different in this sense.

Fook (2008) investigates the level of ICT use for educational purposes by teachers in Jordanian rural secondary schools. The data for the study were collected through the use of quantitative data. A questionnaire was distributed to 650 teachers in Jordan. The findings of the study revealed that teachers had a low level of ICT use for educational purpose; teachers hold positive attitudes towards the use of ICT, and a significant positive correlation between teachers' level of ICT use and their attitudes towards ICT was four. Fook study is lacking one thing. This study was done in rural secondary school where ICT technology is not usually available. He used quantitative methodology for his research. The current study also was guided by above mentioned methodology. Co-relationship had been measured by fook and present study will also measure correlation between different variables of different hypothesis.

Jimoyiannisa and Komis (2007) examine current teachers' beliefs and attitudes towards information and communication technologies (ICT) in education. Multivariate analysis identified three groups of teachers that exhibited a steady loom: a group of teachers having affirmative attitudes towards the objects of the making inquiries, a second group with off-putting attitudes and a third one with disinterested beliefs about ICT in education. The researcher found that personal factors (subject theme, teaching know-how and gender) are strongly allied with the thinking and perceptions teachers hold about ICT.

Gulbahar and Guven (2009) studied sheds light on the use of ICT tools in primary schools in the social studies subject area, by taking into consideration a mixture of variables which influence the accomplishment of the completion of the use of these tools. A study was concluded on 326 teachers who educate fourth and fifth ranking at primary level. The results showed that although teachers are willing to use ICT resources and are aware of the existing potential, they are in front of troubles in relation to convenience to ICT possessions and shortage of inservice teaching opportunities. This study helped the researcher of present study to a greater extent. As SPSS and statistical test are used to measure relationship between different variable. The present research is different in the sense that it is going to be done on universities, where there ICT resources are available.

Ssewanyana and Busler (2009) examined the extent of adoption and usage of ICT on one hundred and ten firms in Uganda; and established benchmarks that can be utilized in future research and comparison between firms. The outcome exposed that the implementation and practice of ICT by firms in emergent countries chase the similar model as in industrial countries, and they only diverge in the level of usage and adoption. Firms do welcome the input of ICT to their presentation, but there are different barriers which have need of governments to take on suitable policies to address them. The factors which are creating hurdle in ICT promotion are not clearly mentioned yet. Then the researcher is only focusing that it is giving advantage only to firms. It did not mentioned, yet it giving bene- 
fits to workers. Researcher of the present research will not only try to count advantages of one sect, taken by the ICT. It will cover all advantages taken by students, teachers, and other faculty.

Akbulut, Kesim and Odabasi (2009) analyzed psychometric facial appearance of a range which was developed to calculate indicators of Information and Communication Technologies (ICT) at an apprentice organization in Turkey. Issues making victorious ICT incorporation were recognized according to competencies declared by UNESCO (2002). Besides, each competency sheltered further sub-components which were adapted from UNESCO (2002) and Odabasi et al. (2006). The survey was administered to 359 education college students at a Turkish state university. Probing dynamic investigation eliminated 13 of 54 questions in the range acknowledged 10 factors accounting for $51.557 \%$ of the discrepancy. The inside reliability was also high (.888). The mentioned study only put focus on the quantification of data. So many factors, which can effect the result are missing it is not mentioned to what extent teachers are taking advantage and teachers expertise in ICT. The present study will put focus on these factors.

Arshad (2009) looked into information systems success representation that can be developed to give details and forecast the victory of e-education systems execution. It identifies constructs to measure e-education systems implementation success; investigates the appropriate dependent variable as a proxy for e-education systems implementation success and finally develops and validates the model. The conclusion from this study showed that the "organizational IS continuance" construct is a feasible alternative for information systems completion success and the sculpt developed can be equally applied. The mentioned research used causal model which helped out the researcher of present study to a greater extent.

Ali (2009) attempts to describe the conditions that facilitated the implementation of Information \& Communication Technology (ICT) integration in the Malaysian elegant discipline and the troubles that come out through the process of integration. The findings revealed that teachers in this study employed four levels of approaches in integrating ICT in the schools. Time, course content and technical malfunction were found to be the main problems that the teachers faced during this process. The present study is different from Ali's research in the sense that Ali's research is focusing on the problems, caused during implementation of ICT technology. While present research is focusing on the factors like availability of resources, utilization of ICT resources, expertise in ICT etc.

Su (2009) in this paper, first demonstrates why a systemic change is needed for effective technology integration in Kindergarten through Grade 12 (K-12). After that, by reviewing the pertinent literature on hurdles to equipment addition, she points out the most fundamental barriers. Lastly, the stages of modify that individuals be inclined to go from side to side in the background of K-12 technology integration is discussed. Her study is lacking in the sense that she could not answer, on which level of education, the barriers are creating hurdle. She could not clearly mention, on which level she studied. Present study is much specific which will try to trace this barrier only at university level. Su's study is helpful for the present research in the sense that it provided new dimension of measuring beliefs of the teachers to use ICT technology.

Huang (2010) aims to examine the feasibility of the student-centered teaching model Utilized in an English audio- video speaking class (EAVSC) in computer-assisted language learning (CALL) environments at the authors' university by hauling out two quantitative longitudinal case studies. Analysis of correlated data show that this precise teaching sculpt in general is both plausible and effective in improving students' communicative language abilities, especially in their speaking abilities. The mentioned research is lacking the variable of "availability of ICT resources". Then the belief and practices of teachers are not mentioned.

Yoshida (2010) in this article describes the background, process of the revision, and the features of the new curriculum standards. The formative evaluation involved 33 teachers' consultants and social education consultants who took part in the "Media Specialists Training Course" which was held by the Ministry of Education, Culture, Sports, Science and Technology (MEXT) in October 2009. As a consequence, most of the subjects reported positive opinions about the new "curriculum standards". Therefore, it is suggested that the new "curriculum standards" is necessary and useful to enhance teachers' knowledge and skills. The mentioned study only focused on teachers. To what extent teachers got benefit from the latest technology while the researcher in the present study will also try to know the perspective of students, in eyes of teachers.

Sunzuma (2011) in this research surveyed 100 A' Level students' views on the ease of use of ICT utensils and assets and their attentiveness in conditions of computer literacy to productively mix ICT assets in learning organic chemistry concepts. The study revealed students had no ready access to computers. Computer practice for knowledge purposes and other uses was relatively low. Schools had no Computer Aided Instruction (CAI) software. However, the students agreed to a larger extent that integrating ICT in teaching and learning of chemistry enhances conceptual understanding of organic chemistry. The mentioned research guided the researcher in many aspects. The researcher of present study got idea about computation of all quantitative analysis from it. Sunzuma made categories of people, who had very accessible, limited access, very limited access not accessible toward ICT resources. But he could not tell, that to what extent this categorization did matter on the belief and practices of students and teachers.

Dalgarno (2008) explores first year teacher education student attentiveness to use ICT in the classroom. The consequences propose that in spite of the prevailing observation that this age group of University students are "Digital Natives", there are a number of hurdles to their thoughtfulness to use ICT in the classroom. In meticulous the study suggests that as fine as looking at the teacher education prospectus and other aspects of the prescribed training of these pre-service teachers, the preservice teachers' personal preparedness including attitude, motivation, and self-reliance, along with different communal factors are important. The study of dalgarno lacking the aspect that what extent the teachers have expertise in the ICT technology. The present study will also measure the expertise of teacher.

Polly (2011) in this study examined elementary school teachers' learning while creating technology-rich instructional materials. Sixteen teachers at an elementary school were interviewed about their experience. Using the components of Technological Pedagogical and Content Knowledge as an analytical framework, inductive qualitative analysis indicated that these professional learning activities led to teachers' growth primarily in technological knowledge, technological pedagogical knowledge and content knowledge. This study was lacking authenticity in 
the sense that only 16 respondents were studied in the whole research which results is not much valid to generalize. The investigator of the at hand study is going to use the same logic of induction as used by polly.

ZHU (2008) in his study centers on the complex interplay of a figure of interior teacher variables to explain ICT classroom integration. The consequences illustrate that classroom use of ICT directly depends on teachers' computer motivation and the supportive use of ICT. Teachers' constructivist beliefs, their attitudes towards computers in education and perceptions about the ICT-related school strategy control ICT mixing in an indirect way. The mentioned study hardly explores the combined impact of factors effecting ICT adoption and integration into education while in the present study all factors like ICT adoption, its integration, its expertise and its availability will be examined.

\section{Research Questions}

The major questions of this research are as follows:

1) Is there any association between level of teachers' age and quantity of daily time spent on computer?

2) Is there any association between category of teachers' gender and quantity of daily time spent on computer?

\section{Research Methodology}

Researcher has used the quantitative method of research. The researcher selected universities in Lahore, Punjab, Pakistan as population of the research. In the present study purposive sampling (nonrandom) is used. Sample of 57 respondents was selected. For this purpose one percent formula was used. First of all, researcher counted all the academic staff in the government universities of Lahore. After counting the whole number a grand total of 5630 was acquired. This figure was divided by 100. The respond was 57 . So, 57 respondents were selected as sample. The number of academic staff and name of universities are as follows:

1) University of education, Lahore. (560)

2) University of Lahore. (920)

3) University of engineering and technology, Lahore. (970)

4) University of veterinary and animal sciences, Lahore. (820)

5) University of the Punjab, Lahore. (2360)

Questionnaire was used as data collection tool in this research. The questionnaire was close ended. The technique of data collection was survey. Pre-testing is done with the purpose to estimate the weaknesses in the data collection tool. Pre-testing was done on six respondents. After pre-testing, necessary changes were introduced in the questionnaire. Two questions were dropped and three were added. One question was modified and one was distributed in different categories. Likert scale was used in this study to measure the intensity of liking or disliking to some argument.

Chi-square test was applied for testing the association between different variables. The formula of chi-square was as follows:

$$
x^{2}=\frac{\sum\left(f_{o}-f_{e}\right)^{2}}{f_{e}}
$$

Then gamma was used to measure the intensity of association between different variables. All required computation was made on SPSS (statistical package for social sciences).

\section{Descriptive Analysis}

Data in the Table 1 were showing the age of respondents. The age is varying form 26 to 50 . Categories were made with interval of five. From the age of 26 to 30 , there were 12 respondents out of 57 . Certain number of respondents belong to 31 to 35 being of age. 12 respondents also belong to the 36 to 40 level of age and people who belong to 41 to 45 level of age, are 12 in number. Only 9 respondents belong to the level of age that varies form 46 to 50 . The data were showing that in each age category, the number of respondent is equal. The researcher himself manipulated this equality, because the researcher wanted to use level of age as independent variable. This is why; he adopted equal number of respondents from each category of age.

Data in the Table 2 were depicting the number of respondents, belonging to the categories of gender. 50.87 percent respondents belong to the category of male. While 49.12 belong to the category of female. There is almost equal number of both male and female. This equality was adjusted by the researcher himself, because he wanted to use gender as an independent variable. So, equal number of male and female respondents was required.

Data in the Table 3 were showing the percentages and frequencies of respondents who have the availability of personal computer at office. It was observed that 89.47 percent respondents are of the view that they have the availability of personal computer at office. While, 10.52 percent respondents have no availability of personal computer at office.

Data in the Table 4 were showing the categories of respondents in regard to availability of internet to each of the respondents. Table is showing that 84.21 percent respondents have the availability of internet at office for personal use.

Data in the Table 5 were showing the categories of respondents from view point of daily time spent on computer.

Table 1.

Distribution of respondents regarding their age.

\begin{tabular}{ccc}
\hline AGE & Frequency & $\%$ \\
\hline (a) $26-30$ & 12 & 21.05 \\
(b) $31-35$ & 12 & 21.05 \\
(c) $36-40$ & 12 & 21.05 \\
(d) $41-45$ & 12 & 21.05 \\
(e) $46-50$ & 9 & 15.78 \\
\hline
\end{tabular}

Table 2.

Distribution of respondents regarding their gender.

\begin{tabular}{ccc}
\hline Gender & Frequency & $\%$ \\
\hline Male & 29 & 50.87 \\
Female & 28 & 49.12 \\
\hline
\end{tabular}

Table 3.

Distribution of respondents in regard to the availability of personal computer at office.

\begin{tabular}{ccc}
\hline Computer Availability & Frequency & $\%$ \\
\hline (a) Yes & 51 & 89.47 \\
(b) No & 6 & 10.52 \\
\hline
\end{tabular}


Table 4.

Distribution of respondents in regard to availability of internet at office for personal use.

\begin{tabular}{ccc}
\hline Internet Availability & Frequency & $\%$ \\
\hline (a) Yes & 48 & 84.21 \\
(b) No & 9 & 15.78 \\
\hline
\end{tabular}

Table 5.

Distribution of respondents from view point of daily time spent on computer.

\begin{tabular}{ccc}
\hline Time Spent (Hours) & Frequency & $\%$ \\
\hline (a) $0-1$ & 3 & 5.26 \\
(b) $1-2$ & 9 & 15.78 \\
(c) 2 - 3 & 18 & 31.57 \\
(d) $3-4$ & 3 & 5.26 \\
(e) $4-5$ & 24 & 42.10 \\
\hline
\end{tabular}

\section{Testing of Hypotheses}

\section{Hypothesis 1}

In this hypothesis association between independent variable (level of age) and dependent variable (time spent on computer) is measured. Null and alternative hypothesis are as follows.

$\mathrm{H}_{0}$ : There is no association between level of age and daily time spent on computer.

$\mathrm{H}_{1}$ : There is association between level of age and daily time spent on computer.

Data in the above Table 6 were showing, how level of age and daily time spent on computer are associated. Level of age ranged from 26 to 50 . While time ranged from zero to five hours. People, who use computer from four to five hours daily, belong to lower range of age. As we increase the age, the number of daily hours spent on computer decrease. So this table is showing a negative relationship between two variables.

To measure the association chi-square test was applied. Data in the Table 7 were showing that degree of freedom is 16 . Level of significance is .05. By using these two values we calculated the tabulated value, which is 26.296 . While, the chiSquare value is 59.617, which is greater than the tabulated value. Which means our hull hypothesis is rejected and alternative hypothesis is accepted. Another example, which supports our argument, is that sig. value is .000 while our level of significance is .05 . This also shows that our alternative hypothesis (there is association between two variables) is accepted and null hypothesis (there is no association between two variables) is rejected.

In Table 8 Gamma is used to measure the intensity of association between two variables. Gamma value is -.557 . This shows that there is negative association between two variables. The association is moderate negative. The reason behind this logic may be that young teachers have much access towards computers and old teachers have not much access and they have not much knowledge about computer as compare to the young teachers.

\section{Hypothesis 2}

Here association between independent variable (category of
Table 6.

Level of teachers age * quantity of daily time spent on computer cross tabulation

\begin{tabular}{cccccccc}
\hline & \multicolumn{7}{c}{ Daily time spent on computer (Hours) } \\
\cline { 2 - 7 } & 0 to 1 & 1 to 2 & 2 to 3 & 3 to 4 & 4 to 5 & \\
\hline Level of age & $26-30$ & 0 & 1 & 3 & 0 & 8 & 12 \\
$31-35$ & 0 & 2 & 0 & 3 & 7 & 12 \\
& $36-40$ & 0 & 1 & 6 & 0 & 5 & 12 \\
& $41-45$ & 0 & 0 & 9 & 0 & 3 & 12 \\
& $46-50$ & 3 & 5 & 0 & 0 & 1 & 9 \\
\multicolumn{1}{c}{ Total } & 3 & 9 & 18 & 3 & 24 & 57 \\
\hline
\end{tabular}

Table 7.

Chi-square tests.

\begin{tabular}{cccc}
\hline & Value & Df & Asymp. Sig. (2-sided) \\
\hline Pearson Chi-Square & 59.617 & 16 & 0 \\
Likelihood Ratio & 56.366 & 16 & 0 \\
Linear-by-Linear Association & 15.183 & 1 & 0 \\
N of Valid Cases & 57 & & \\
\hline
\end{tabular}

Table 8.

Symmetric Measures.

\begin{tabular}{lcccc}
\hline & Value & Asymp. Std. Error & Approx. T Approx. Sig. \\
\hline $\begin{array}{l}\text { Ordinal by } \\
\text { Ordinal }\end{array}$ Gamma & -.56 & .127 & -3.974 & 0 \\
N of Valid Cases & 57 & & & \\
\hline
\end{tabular}

teachers' gender) and dependent variable (daily time spent on computer) is measured through using chi-square. The researcher made null and alternative hypotheses in the following manner:

$\mathrm{H}_{0}$ : There is no association between category of gender and daily time spent on computer.

$\mathrm{H}_{1}$ : There is association between category of gender and daily time spent on computer.

Data in the Table 9 were showing the association between category of gender and daily time spent on computer gender is categorized in male and female. The intention was to measure whether male or female have any variation in daily time spending on computer? But there is no viable relationship. Changing the category of gender has no impact over the dependent variable.

In Table 10, chi-square test was applied. Level of significance was adjusted at .05 . While Table $\mathbf{1 0}$ is showing the Sig. Value is .098. Which is meaning that null hypothesis is accepted and alternative hypothesis is rejected. Then tabulated value was also calculated against 4 degree of freedom. And the tabulated value was 9.488 , which was greater than chi-Square value, which were 7.818 , which proved that there was no association between independent and dependent variables. The reason behind this no association may be that now male and female both have access to computer and their Job related tasks are quit Similar during teaching.

\section{Conclusions \& Recommendations}

\section{Conclusion}

To measure the perception of university teachers about ICT 
Table 9.

Category of teachers' gender * quantity of daily time spent on computer. Cross tabulation:

\begin{tabular}{ccccccccc}
\hline & & \multicolumn{5}{c}{$\begin{array}{c}\text { Daily time spent on computer } \\
\text { (hours) }\end{array}$} & \\
\cline { 2 - 7 } & & 0 to 1 & 1 & to 2 & 2 to 3 & 3 to 4 & 4 to 5 & \\
\hline $\begin{array}{c}\text { Category of teachers' } \\
\text { Gender }\end{array}$ & Male & 2 & 6 & 12 & 0 & 9 & 29 \\
Total & Female & 1 & 3 & 6 & 3 & 15 & 28 \\
& & 3 & 9 & 18 & 3 & 24 & 57 \\
\hline
\end{tabular}

Table 10.

Chi-square tests.

\begin{tabular}{cccc}
\hline & Value & df & Asymp. Sig. (2-sided) \\
\hline Pearson Chi-Square & $7.818^{\mathrm{a}}$ & 4 & .098 \\
Likelihood Ratio & 9.055 & 4 & .06 \\
Linear-by-Linear Association & 4.301 & 1 & .038 \\
N of Valid Cases & 57 & &
\end{tabular}

integration into educational institutions of Pakistan, two hypotheses were made. The conclusions of these hypotheses are being elaborated in the following situation.

In the first hypothesis, it has been concluded that by increasing the level of teachers' age, the quantity of daily time spent on computer decreases. The age varies from 26 to 50 . Interval of five was adjusted. In each age group, equal number of respondents were included. The association between two hypotheses was moderate negative. The reason may be that as the age grows the responsibilities of person increase and usage of computer, in routine life, decreases.

The conclusion of second hypothesis shows that there is no association between category of teachers' gender and quantity of daily time spent on computer. This is because in the educational institutions both male and female are provided with equal ICT facilities.

\section{Recommendations}

Keeping in mind the above mentioned conclusion, follow recommendations which are made to improve the rate of ICT integration into educational institution.

1) Education policies should focus on the enhancement of modern technologies in the field of education. A valuable amount should be specified for education sector in the budget. Computers, internet, multimedia, large screens and other technological devices and instrument should be provided in schools, colleges and universities.

2) Pakistan must have good relationship with the countries that have a good name in modern technology. Pakistan should borrow technological advancements from these countries. Pakistan should not only take material technology, like laptops, computers and other hardware, but also borrow nonmaterial technology, which means skills to use technology.

3) In the educational institutions, provision of ICT should be without gender biasness. Male and female should have equal opportunities to the ICT in the institutions.

4) Not only the students, but also teachers should also be given with ICT technology.

5) Another important element is that teachers should be given with training of using these technologies.
6) Private sector, NGOs, trusts and other private foundations that are serving the humanity, should also serve the education sector for the implement of ICT. This examination may be in the form of provision of technological equipment as well as technological skills.

7) There are certain religious ideologies, which are becoming a hurdle. Such kind of strict ideologies should be minimized.

8) Seminars should be organized which must elaborate the significance of latest technology in educational field. Such seminars should motivate students as well as teachers to adopt modern technology in educational field.

\section{REFERENCES}

Adeyinka, T. (2007). An assessment of secondary school teachers uses of ICTs. International Journal of Education and Development Using ICT, 3.

Akbulut, Y., Kesim, M., \& Odabasi, F. (2009). Construct validation of ICT Indicators Measurement Scale (ICTIMS). Eskişehir: Anadolu University.

Ali, W. Z. (2009). The conditions and level of ICT integration in Malaysian Smart Schools. International Journal of Education and Development Using ICT, 5, 21-31.

Arshad, N. H. (2009). E-education systems implementation success model. Selangor.

Bhukuvhani, C., Zezekwa, N., \& Sunzuma, G. (2011). Students' preparedness to integrate information and communication technology tools and resources for the learning of organic chemistry concepts in the District of Masvingo, Zimbabwe. International Journal of Education and Development Using Information and Communication Technology (IJEDICT), 7, 27-37.

Dalgarno, B. (2008). Influences on pre-service teachers' preparedness to use ICT in the classroom. Lincoln Gill Centre for Enhancing Learning and Teaching, Charles Sturt University.

Ertmer, P. A. (2005). Teacher pedagogical beliefs: The final frontier in our quest for technology integration? Educational Technology Research and Development, 53, 25-39. http://dx.doi.org/10.1007/BF02504683

Fook, F. S. (2008). Teachers' attitudes and levels of technology use in classrooms. Pulau Penang: University of Sains.

Gulbahar, S., \& Guven, I. (2009). A survey on ICT usage and the perceptions of social studies teachers in Turkey. Ankara: Baskent University.

Jimoyiannisa, A., \& Komisb, V. (2007). Examining teachers' beliefs about ICT in education: Implications of a teacher preparation programme. Peloponnese: University of Peloponnese.

Polly, D. (2011). Teachers' learning while constructing technologybased instructional resources. British Journal of Educational Technology, 42, 950-961. http://dx.doi.org/10.1111/j.1467-8535.2010.01161.x

Reigeluth, C. M. (1995). Educational systems development and its relationship to ISD. In G. Anglin (Ed.), Instructional technology: past, present, and future (2nd ed.). Englewood, CO: Libraries Unlimited.

Reigeluth, C. M. (1994). The imperative for systemic change. In C. M. Reigeluth, \& R. J. Garfinkle (Eds.), Systemic change in education. Englewood Cliffs, NJ: Educational Technology Publications.

Ssewanyana, J., \& Busler, M. (2009). Adoption and usage of ICT in developing countries. Case of Ugandan firms. Kampala: Makerere University.

Siddiquei, H. (2008). Educational problems of Pakistan. Sindh: PSC, University of Sindh.

Su, B. (2009). Effective technology integration: Old topic, new thoughts. International Journal of Education and Development Using Information and Communication Technology (IJEDICT), 5, 161 171 .

Sunzuma, G. (2011). Students' preparedness to integrate information and communication technology tools and resources for the learning of 
A. ADIL ET AL.

organic chemistry concepts in the District of Masvingo, Zimbabwe. Bindura: Bindura University of Science Education.

Shah, R. A. (2001). Education and teacher education in Pakistan. CA Book of Reading. Sindh: Pakistan Study Centre.

Yoshida, H. (2010). Development and formative evaluation of the educational media in-service teacher training curriculum standards.
International Journal of Education and Development Using Information and Communication Technology (IJEDICT), 6, 37-55.

Zhu, C. (2009). Factors associated with the integration of ICT into Chinese primary school classrooms: An interplay of teacher-related variables. Ghent: Ghent University. 